\title{
The Impact of Cochlear Implantation: Cognitive Function, Quality of Life, and Frailty in Older Adults
}

\author{
Eric E. Babajanian, M.D., ${ }^{1}$ Neil S. Patel, M.D., ${ }^{1}$ and \\ Richard K. Gurgel, M.D., M.S.C.I. ${ }^{1}$
}

\section{ABSTRACT}

This review examines the relationship between cochlear implantation and cognition and quality of life in older adults, as well as how frailty affects outcomes for older patients with cochlear implants. A growing body of evidence suggests that there is a strong association between hearing loss and cognitive impairment. Preliminary studies suggest that cochlear implantation in older adults may be protective against cognitive decline. While studies have observed a positive impact of cochlear implantation on quality of life, currently it is unclear what factors contribute the most to improved quality of life. Frailty, as a measurement of general health, likely plays a role in complication rates and quality-of-life outcomes after cochlear implantation, though larger prospective studies are required to further elucidate this relationship.

KEYWORDS: cochlear implant, cognition, quality of life, frailty

\begin{abstract}
Age-related hearing loss (ARHL), or presbycusis, occurs in most individuals as they grow older and, according to the World Health Organization, can result in disabling hearing loss in around one-third of individuals older than 65 years. ${ }^{1}$ This prevalence of ARHL rises to greater than $80 \%$ in individuals older than 85 years. ${ }^{2}$ With presbycusis, sensorineural hearing loss will typically begin in the high-frequency range in a symmetric fashion with progressive spread toward the low-frequency
\end{abstract}

range as individuals continue to age. Causal factors of presbycusis likely include the synergistic effect of intrinsic factors such as genetic predisposition and epigenetic factors in addition to extrinsic factors such as noise exposure, ototoxic drug exposure, tobacco use, and alcohol abuse. ${ }^{3}$ There are currently no widely accepted protocols for screening for ARHL in older adults. ${ }^{4,5}$

Presbycusis, especially if left untreated, can have a significant impact on an individual's life
${ }^{1}$ Division of Otolaryngology-Head and Neck Surgery, Department of Surgery, University of Utah, Salt Lake City, Utah.

Address for correspondence: Eric Babajanian, M.D., Division of Otolaryngology, University of Utah School of Medicine, 50 North Medical Dr., SOM 3C120, Salt Lake City, UT 84132 (e-mail: eric.babajanian@hsc.utah.edu).
Barriers to Cochlear Implant Access: Acknowledging the Challenges, Changing the Future; Guest Editor, Sarah Sydlowski, Au.D., Ph.D., M.B.A.

Semin Hear 2021;42:342-351. (C) 2021. Thieme. All rights reserved. Thieme Medical Publishers, Inc., 333 Seventh Avenue, 18th Floor, New York, NY 10001, USA DOI: https://doi.org/10.1055/s-0041-1739367.

ISSN 0734-0451. 
and is an independent risk factor for the development of dementia or cognitive decline. ${ }^{6-10} \mathrm{It}$ is estimated that hearing loss may account for 9\% of risk for Alzheimer's disease dementia, making it the largest single modifiable risk factor. ${ }^{11}$ The exact mechanism of how presbycusis contributes to cognitive impairment, however, remains unknown. Previous studies have discussed psychosocial factors, neuroanatomic changes, cognitive load, or artifact of cognitive test scoring due to hearing loss as potential explanations. ${ }^{8,12-14}$ Alzheimer's disease causes differential changes in the auditory cortex, which may explain an underlying mechanism. ${ }^{15}$ While the etiology explaining the link between hearing loss and cognitive impairment remains unknown, it is likely multifactorial and varies on an individual basis.

Cochlear implantation is a well-established means to restoring nonserviceable severe to profound sensorineural hearing loss that has been shown to be both safe and efficacious in older adults. ${ }^{16-21}$ Previous studies have also shown that older adults who undergo cochlear implantation have a similar learning curve and hearing outcomes as younger adults, and that cochlear implantation can have a significant impact on quality of life in the elderly. ${ }^{18,22}$ Aural rehabilitation using hearing aids results in either higher cognitive scores or a lower rate of decline in cognitive assessment scores. ${ }^{6,23-25}$ Less is known, however, about the potential impact cochlear implantation has on cognitive function in this patient cohort, in part due to the baseline differences in hearing function and the difference between acoustic and electric hearing rehabilitation.

Necessary to the preoperative evaluation for older cochlear implant candidates is a thorough medical evaluation to ensure that medical comorbidities or poor functional status would not elevate surgical risk to the point that implantation would not be offered. An objective measure to quantifying a patient's overall health and functional status is the frailty index, which takes into account the accumulation of health deficits during an individual's life as a reflection of their overall severity of illness and proximity to death. ${ }^{26}$ Several studies have demonstrated the safety of cochlear implantation in the older adult population, but few have evalu- ated the correlation between medical comorbidities and cochlear implantation outcomes. ${ }^{27,28}$

This report reviews the impact of cochlear implantation on cognitive function and quality of life in older adult cochlear implant recipients in addition to the role of frailty in cochlear implant outcomes.

\section{COGNITIVE FUNCTION}

\section{The Relationship Between Hearing Loss and Cognitive Function}

Life expectancy has continued to increase in most industrialized countries over the past decade. Despite the notion that individuals are reaching older age in better health and thus delaying death, it is well-known that the number of age-related chronic conditions that negatively impact daily life and independence also has increased. ${ }^{29,30}$ Understanding which modifiable factors contribute to the decline in overall cognitive function and the development of dementia is the subject of increasing research.

Several studies have now demonstrated the advanced rate of cognitive decline in older adults with hearing loss compared with those with normal hearing. In a cross-sectional study evaluating 347 participants older than 55 years, Lin et al demonstrated that worse hearing loss was independently associated with lower scores on tests of mental status, memory, and executive function. ${ }^{10}$ With prospective data obtained as part of the Health, Aging and Body Composition study, Deal et al reported an increased risk of developing dementia in patients aged 70 to 79 years with moderate to severe hearing loss. ${ }^{31}$ Over the past several years, multiple additional studies have reported consistent results supporting the notion that hearing loss in the older adult population is associated with an increased risk of developing dementia. ${ }^{7,32-35}$

An area of active research is elucidating why there is a relationship between hearing loss and cognitive decline. Multiple hypotheses have been proposed, including psychosocial factors, cognitive load, neuroanatomic changes, the deprivation hypothesis, the common cause hypothesis, and the potential artifact of cognitive test scoring due to hearing loss as potential explanations. ${ }^{8,12-14}$ Hearing loss, especially in 
older individuals, often results in social isolation due to difficulty with communication and maintaining relationships. ${ }^{36}$ Social isolation has been shown to increase the risk for cognitive decline and the development of dementia. ${ }^{37}$ The cognitive load hypothesis refers to the explanation that mental resources are diverted to auditory perception in the setting of hearing loss. ${ }^{14}$ Regarding neuroanatomical changes, it is likely that a combination of peripheral and central changes, including decreased relative volume and cortical thickness of the prefrontal cortex and decreased auditory association cortex gray matter density, leads to declining speech perception in noise. ${ }^{12,15}$ Along these lines, the "deprivation" hypothesis refers to the notion that hearing loss affects brain integrity. This hypothesis is based on findings that older adult patients with hearing loss exhibited accelerated whole brain atrophy, particularly in the right temporal lobe, and lower total brain volume. $^{38,39}$ The "common cause" hypothesis refers to the possibility that both hearing loss and cognitive decline arise from the same neurodegenerative process associated with old age. ${ }^{40,41}$ Lastly, it is important to consider that some cognitive function tests, including the Mini Mental State Exam (MMSE) and the Montreal Cognitive Assessment (MoCA), rely on auditory processing, and that scores for these tests can be significantly impacted if an individual suffers from disabling hearing loss. ${ }^{42,43}$

Recently, insulin-like growth factor 1 (IGF-1) has been identified as a potential mediator of cognition and hearing loss. In animal and human models, inborn IGF-1 deficiency results in a phenotype characterized by profound hearing loss, cognitive deficits, and short stature. ${ }^{44}$ Based on this and its role as a neuroprotective agent, a decline in IGF-1 levels has been implicated in the progression of ARHL and, either as a result of hearing loss or through a direct influence on the nervous system, a decline in cognitive performance. ${ }^{45}$

Unlike other sensory deficits, hearing loss may be the most modifiable. In an updated 2020 report of the Lancet Commission on dementia prevention, preventing hearing loss, treating hearing impairment, and maintaining social contact were identified as critical factors in increasing and maintaining cognitive reserve. ${ }^{11}$
An analysis conducted within the PAQUID study, which is a French prospective population-based study involving 3,777 participants aged 65 years and over, showed that self-perceived hearing loss was associated with lower MMSE scores at baseline in addition to a greater rate of decline over the 25-year follow-up period. ${ }^{23}$ Interestingly, those patients who did have self-perceived hearing loss at the beginning of the study and wore hearing aids had a similar rate of decline in MMSE scores as the normal hearing group, whereas those with self-perceived hearing loss who did not wear hearing aids had a greater rate of decline compared with the normal hearing group. Conversely, in a recent review, Amieva and Ouvrard concluded that while there is a clear association between dementia and hearing loss, there continues to be limitations of the existing literature in terms of establishing a convincing argument on the positive effect of hearing aids and cochlear implants on cognition. ${ }^{30}$ While there are a few other longitudinal studies evaluating the impact of treating hearing loss, ${ }^{24,25}$ there continues to be a lack of randomized trials evaluating the interventional impact of hearing aids on cognitive function, though studies are underway, notably the Aging and Cognitive Health Evaluation in Elders (ACHIEVE) study. ${ }^{46}$ Nonetheless, the available literature suggests that hearing aid use likely does have a positive impact on cognitive function in older adults with hearing loss.

\section{The Impact of Cochlear Implantation on Cognitive Function}

Several studies have examined the impact of hearing aids on cognitive decline, but few have looked specifically at cochlear implantation. A systematic review conducted by Miller et al in 2015 found that there were only three studies conducted in the English literature that evaluated cognition as the primary outcome measure of cochlear implantation in adults older than 65 years. ${ }^{47-50}$ These three studies were published several years ago and the technology used would now be considered obsolete. Moreover, the primary rationale of these studies was largely to evaluate adverse neurocognitive effects of the cochlear implantation procedure itself. 
Since 2015, the need for further clinical research on the neurocognitive impact of cochlear implantation has become increasingly recognized. Prospective longitudinal studies have observed improvements in global cognitive function, including processing speed, cognitive flexibility, inhibition, attention, and working memory, as early as 6 months after cochlear implantation. ${ }^{51-54}$ Mosnier et al conducted a prospective longitudinal study examining the relationship between cochlear implantation and cognitive function, instituting a battery of six tests implemented before implantation and both 6 and 12 months postimplantation. ${ }^{51}$ The majority of the patient cohort with poor cognitive scores prior to implantation (30 of 37 patients) showed improved global cognitive function at 12 months postimplantation, with cognitive function remaining stable in the other seven patients. A 7-year follow-up study of this same cohort demonstrated a lower rate of progression of mild cognitive impairment to dementia (6\% at 7 years after implantation) compared with longitudinal population-based studies that reported more than $50 \%$ progression within 5 years. ${ }^{55}$ Sarant et al have undertaken a 5 -year longitudinal study examining the impact of cochlear implants on cognitive function. ${ }^{56} \mathrm{At}$ 18 months, significant benefits have been observed in speech perception, quality of life, and communication ability. Furthermore, there has been no significant decline on any cognitive test score. A recent prospective interventional study by the authors of the present report enrolled cochlear implant participants older than 65 years and demonstrated a parallel improvement in hearing and cognitive function test scoring, especially in patients with cognitive impairment prior to cochlear implantation compared with those with normal cognition. ${ }^{57} \mathrm{~A}$ visual abstract of how cochlear implants affect brain function is depicted in Fig. 1.

\section{COCHLEAR IMPLANTATION AND QUALITY OF LIFE IN OLDER ADULTS}

Cochlear implantation is now the established standard-of-care treatment for patients with advanced sensorineural hearing loss that

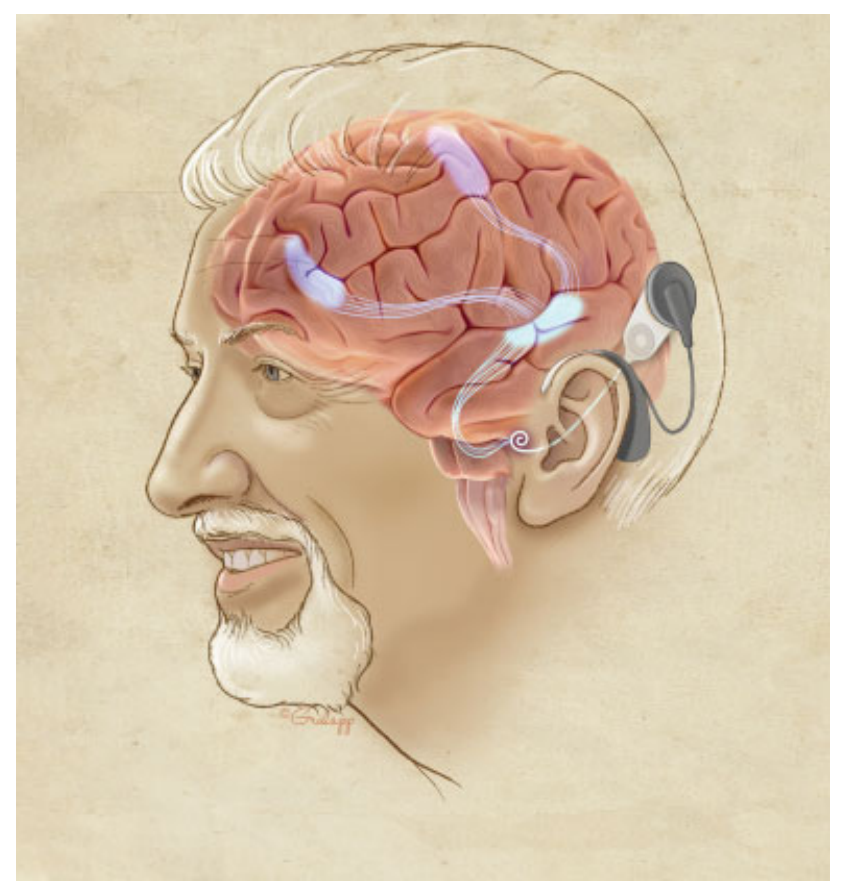

Figure 1 Description of how a cochlear implant can deliver auditory stimuli that activate various brain regions in older adults with severe-profound hearing loss. The stimuli activate the auditory association cortex which projects to other brain regions such as the premotor cortex that assists with attention and the frontal cortex. (Reproduced with permission from (C) Chris Gralapp.) 
receive limited benefit from conventional amplification. Standard outcome measures to suggest whether cochlear implantation is successful for an individual generally revolve around open-set word and sentence recognition. ${ }^{58}$ While this provides one objective measure of improvement after surgery, hearing outcomes alone fail to encapsulate the qualitative benefit cochlear implantation may provide an individual. Though this has not been formally studied, regaining sound input alone after cochlear implantation-regardless of objective results measured by outcome measures-may in itself have positive effects on cognition.

Quality-of-life improvement, as measured through patient-reported outcome measures, encompasses many aspects of a patient's life, including the impact of physical and mental health on daily life. General quality-of-life measurement instruments have been used to evaluate the quality-of-life impact of cochlear implantation. The Health Utilities Index Mark 3 (HUI3) and the Australian Assessment of Quality of Life (AQoL), for instance, are generic utility measures that include assessments of well-being and communication difficulties. ${ }^{59,60}$ These assessment tools are particularly useful for cost-utility analysis. One of the most frequently used disease-specific scales is the Nijmegen Cochlear Implantation Questionnaire (NCIQ), a quantifiable self-assessment tool developed specifically to assess health-related quality-of-life measures in three domains (physical, psychological, and social) for individuals who have undergone cochlear implantation, and is often used in studies evaluating the impact of cochlear implantation on patients' lives. ${ }^{61}$ More recently, McRackan et al have developed the Cochlear Implant Quality of Life (CiQOL) instruments to analyze six domains influenced by cochlear implantation (communication, emotional, entertainment, environment, listening effort, and social). ${ }^{62,63}$ Ultimately, studies using CiQOL pre- and postoperatively may be able to characterize the impact of cochlear implantation on these specific aspects of a patient's life. Other disease-specific scales include the Glasgow Benefit Inventory (to measure the impact of an otolaryngologic intervention), Hearing Handicap Inventory for Adults/Elderly (HHIE), and
Speech Spatial and Qualities of Hearing Scale (SSQ). ${ }^{64-67}$

In general, studies evaluating the impact of cochlear implantation on quality of life have revealed a largely positive effect after cochlear implantation. Hirschfelder et al evaluated 56 patients using the Nijmegen Cochlear Implant Questionnaire (NCIQ) and reported significant improvements in all subdomains after cochlear implantation. ${ }^{68}$ Similar results have been reported by multiple other studies, including postlingually deaf, unilateral implants, bilateral implants, and unilateral implants for singleside deafness. ${ }^{69-73}$ McRackan et al evaluated the association among demographic, hearingrelated, and cochlear implant-related factors and quality of life, and found that higher household income, longer duration of hearing loss prior to implantation, bilateral implantation, and better sentence recognition ability using AzBio testing were associated with higher quality-of-life scores. ${ }^{74}$ Interestingly, they noted the included demographic, hearing-related, and cochlear implant-related factors accounted for a small percentage of the variance seen in the quality-of-life domain scores, suggesting that factors that contribute to cochlear implantrelated quality-of-life scores are not encompassed by these domains.

Interestingly, studies have reported conflicting results regarding whether quality-of-life measures correlate with objective speech perception scores. A meta-analysis by McRackan et al evaluating 14 articles with 679 patients who underwent cochlear implantation found that there was a significant improvement in both hearing-specific and cochlear implantspecific quality-of-life measures. ${ }^{75}$ However, they found that currently used clinical measures evaluating speech recognition are poor predictors of patient-reported hearing-specific and cochlear implant-specific quality-of-life scores. Hirschfelder et al utilized the Freiburg monosyllable and Hochmair, Schulz, Moser (HSM) sentence test for speech perception testing and noted that speech perception scoring correlated with the positive effect on quality of life noted by the NCIQ. ${ }^{68}$ Francis et al also reported a moderate correlation between speech recognition and quality-of-life improvements. ${ }^{76}$ On the other hand, Capretta and Moberly found 
that only a few quality-of-life scores correlated with clinical speech recognition measures. ${ }^{77}$ Similar results were reported by Kou et al in older study evaluating Nucleus 22-channel cochlear implant users. ${ }^{78}$ Based on the conflicting results from multiple studies, it is likely that the subdomains included in current quality-of-life instruments are measuring aspects of outcomes after cochlear implantation that are not being included or measured by speech perception assessments, or, as mentioned earlier, the multitude of benefits offered by cochlear implantation in the setting of advanced sensorineural hearing loss are not able to be distilled into a speech understanding test.

\section{FRAILTY}

The prevalence of hearing loss increases with age, and the majority of individuals with severeto-profound hearing loss are older than 65 years. ${ }^{79,80}$ Despite this, only $5 \%$ of individuals who would be cochlear implant candidates actually undergo implantation. ${ }^{81}$ While most agree that access limitations and understanding candidacy are the primary barriers, part of the reason for this low penetrance is likely due to concerns regarding safety of undergoing this procedure, despite multiple studies demonstrating the safety of this procedure in the older adult population. ${ }^{17,27,28}$ This has led the authors of the present report and others to determine whether an objective risk assessment could be used to predict postoperative morbidity and therefore guide decision-making preoperatively.

Frailty refers to the cumulative decline of many physiologic systems with time. ${ }^{82}$ Two ways to evaluate an individual's level of frailty are the frailty phenotype and frailty index. Fried et al described the frailty phenotype, which defines frailty as a syndrome that takes into account unintentional weight loss, self-reported exhaustion, weakness, slow walking speed, and low physical activity. ${ }^{83}$ Despite multiple studies validating this definition, it fails to take into account several potentially important factors, such as cognitive impairment. The frailty index, originally described by Mitnitski et al, was developed to provide a proxy quantifiable measure of aging and mortality that takes into account a patient's symptoms, signs, laboratory/radiographic/electrocardiographic abnormalities, comorbidities, and overall functional status. ${ }^{26}$ The index value is calculated as a ratio of the number of deficits present to the number of deficits considered, and the value is higher for individuals who are generally unwell. Since its original development as a 70 -item scale, the frailty index has been modified and redefined to an 11-factor and 5-factor modified frailty index, both of which are equally effective predictors of mortality and postoperative complications. ${ }^{84}$

The frailty index has been widely validated and used in the surgical literature, but has only been utilized in small set of otolaryngology studies. ${ }^{85-88}$ In a large retrospective study examining the implications of frailty in inpatient otolaryngology procedures, Adams et al found that an increase in the modified frailty index resulted in a significant increase in mortality risk and complications. ${ }^{86}$ At the time this review was written, only one study has examined the impact of frailty on cochlear implantation. Aylward et al conducted a cross-sectional survey on 143 individuals aged 65 years and over to evaluate the relationship between frailty and postimplantation audiologic outcomes and hearing-related quality-of-life scores. ${ }^{89}$ They found that while frailty index does not correlate with audiologic outcomes, a lower frailty index value does predict higher hearing-related quality-of-life scores after implantation, suggesting that older adults who are more frail may experience even greater benefit from improved hearing.

\section{SUMMARY}

As a growing body of evidence is allowing us to better understand the association between hearing loss and cognition, multiple recent prospective studies have shown a positive impact of cochlear implantation on neurocognitive outcomes in older adults. Quality of life is positively impacted by cochlear implantation, but the magnitude of change does not seem to be well characterized by audiologic outcome measures alone. Preliminary studies on the relationship of frailty and outcomes after implantation suggest that patients with higher frailty index value may experience greater improvement in 
quality of life. Future prospective studies are needed to better understand the neurocognitive and quality-of-life impact of cochlear implantation and the role of frailty on audiologic and quality-of-life outcomes.

\section{FUNDING}

None.

\section{CONFLICTS OF INTEREST}

R.K.G. is on the surgical advisory board for Med-El, and receives institutional research funding from Cochlear and Advanced Bionics and the NIH.

\section{REFERENCES}

1. World Health Organization. Addressing the Rising Prevalence of Hearing Loss. World Health Organization; 2018

2. Yueh B, Shapiro N, MacLean CH, Shekelle PG. Screening and management of adult hearing loss in primary care: scientific review. JAMA 2003;289 (15):1976-1985

3. Wang J, Puel J-L. Presbycusis: an update on cochlear mechanisms and therapies. J Clin Med 2020;9(01):218

4. Krist AH, Davidson KW, Mangione CM, et al; US Preventive Services Task Force. Screening for hearing loss in older adults: US Preventive Services Task Force Recommendation Statement. JAMA 2021;325(12):1196-1201

5. Gurgel RK, Briggs SE, Dhepyasuwan N, Rosenfeld RM. Quality improvement in otolaryngology-head and neck surgery: age-related hearing loss measures. Otolaryngol Head Neck Surg 2021 (epub ahead of print). Doi: 10.1177/01945998211000442

6. Deal JA, Sharrett AR, Albert MS, et al. Hearing impairment and cognitive decline: a pilot study conducted within the atherosclerosis risk in communities neurocognitive study. Am J Epidemiol 2015;181(09):680-690

7. Lin FR, Metter EJ, O’Brien RJ, Resnick SM, Zonderman AB, Ferrucci L. Hearing loss and incident dementia. Arch Neurol 2011;68(02):214-220

8. Thomson RS, Auduong P, Miller AT, Gurgel RK. Hearing loss as a risk factor for dementia: a systematic review. Laryngoscope Investig Otolaryngol 2017;2(02):69-79

9. Gurgel RK, Ward PD, Schwartz S, Norton MC, Foster NL, Tschanz JT. Relationship of hearing loss and dementia: a prospective, population-based study. Otol Neurotol 2014;35(05):775-781
10. Lin FR, Ferrucci L, Metter EJ, An Y, Zonderman $\mathrm{AB}$, Resnick SM. Hearing loss and cognition in the Baltimore Longitudinal Study of Aging. Neuropsychology 2011;25(06):763-770

11. Livingston G, Huntley J, Sommerlad A, et al. Dementia prevention, intervention, and care: 2020 report of the Lancet Commission. Lancet 2020;396(10248):413-446

12. Wong PCM, Ettlinger M, Sheppard JP, Gunasekera GM, Dhar S. Neuroanatomical characteristics and speech perception in noise in older adults. Ear Hear 2010;31(04):471-479

13. Parham K, Lin FR, Coelho DH, Sataloff RT, Gates GA. Comprehensive management of presbycusis: central and peripheral. Otolaryngol Head Neck Surg 2013;148(04):537-539

14. Pichora-Fuller MK, Schneider BA, Daneman M. How young and old adults listen to and remember speech in noise. J Acoust Soc Am 1995;97(01): 593-608

15. Aylward A, Auduong P, Anderson JS, et al. Changes in the Auditory Association Cortex in dementing illnesses. Otol Neurotol 2020;41(10): 1327-1333

16. Alice B, Silvia M, Laura G, Patrizia T, Roberto B. Cochlear implantation in the elderly: surgical and hearing outcomes. BMC Surg 2013;13(Suppl2):S1

17. Carlson ML, Breen JT, Gifford RH, et al. Cochlear implantation in the octogenarian and nonagenarian. Otol Neurotol 2010;31(08):1343-1349

18. Lenarz M, Sönmez H, Joseph G, Büchner A, Lenarz T. Cochlear implant performance in geriatric patients. Laryngoscope 2012;122(06):1361-1365

19. Lin FR, Chien WW, Li L, Clarrett DM, Niparko JK, Francis HW. Cochlear implantation in older adults. Medicine (Baltimore) 2012;91(05):229-241

20. Migirov L, Taitelbaum-Swead R, Drendel M, Hildesheimer M, Kronenberg J. Cochlear implantation in elderly patients: surgical and audiological outcome. Gerontology 2010;56(02):123-128

21. Buchman CA, Gifford RH, Haynes DS, et al. Unilateral cochlear implants for severe, profound, or moderate sloping to profound bilateral sensorineural hearing loss: a systematic review and consensus statements. JAMA Otolaryngol Head Neck Surg 2020;146(10):942-953

22. Vermeire K, Brokx JP, Wuyts FL, Cochet E, Hofkens A, Van de Heyning PH. Quality-of-life benefit from cochlear implantation in the elderly. Otol Neurotol 2005;26(02):188-195

23. Amieva H, Ouvrard C, Giulioli C, Meillon C, Rullier L, Dartigues JF. Self-reported hearing loss, hearing aids, and cognitive decline in elderly adults: a 25-year study. J Am Geriatr Soc 2015;63(10): 2099-2104

24. Acar B, Yurekli MF, Babademez MA, Karabulut $\mathrm{H}$, Karasen RM. Effects of hearing aids on 
cognitive functions and depressive signs in elderly people. Arch Gerontol Geriatr 2011;52(03): 250-252

25. Ray J, Popli G, Fell G. Association of cognition and age-related hearing impairment in the English Longitudinal Study of Ageing. JAMA Otolaryngol Head Neck Surg 2018;144(10):876-882

26. Mitnitski AB, Mogilner AJ, Rockwood K. Accumulation of deficits as a proxy measure of aging. ScientificWorldJournal 2001;1:323-336

27. Castiglione A, Benatti A, Girasoli L, et al. Cochlear implantation outcomes in older adults. Hear Balance Commun 2015;13:86-88

28. Sanchez-Cuadrado I, Lassaletta L, Perez-Mora $\mathrm{RM}$, et al. Is there an age limit for cochlear implantation? Ann Otol Rhinol Laryngol 2013; 122(04):222-228

29. Vaupel JW. Biodemography of human ageing. Nature 2010;464(7288):536-542

30. Amieva H, Ouvrard C. Does treating hearing loss in older adults improve cognitive outcomes? A review. J Clin Med 2020;9(03):805

31. Deal JA, Betz J, Yaffe K, et al; Health ABC Study Group. Hearing impairment and incident dementia and cognitive decline in older adults: the Health ABC Study. J Gerontol A Biol Sci Med Sci 2017; 72(05):703-709

32. Gallacher J, Ilubaera V, Ben-Shlomo Y, et al. Auditory threshold, phonologic demand, and incident dementia. Neurology 2012;79(15): 1583-1590

33. Heywood R, Gao Q, Nyunt MSZ, et al. Hearing loss and risk of mild cognitive impairment and dementia: findings from the Singapore Longitudinal Ageing Study. Dement Geriatr Cogn Disord 2017;43(5-6):259-268

34. Amieva H, Ouvrard C, Meillon C, et al. Death, depression, disability, and dementia associated with self-reported hearing problems: a 25-year study. J Gerontol A Biol Sci Med Sci 2018;73(10): 1383-1389

35. Maharani A, Dawes P, Nazroo J, et al. Associations between self-reported sensory impairment and risk of cognitive decline and impairment in the Health and Retirement study cohort. J Gerontol B Psychol Sci Soc Sci 2020;75(06):1230-1242

36. Weinstein BE, Ventry IM. Hearing impairment and social isolation in the elderly. J Speech Hear Res 1982;25(04):593-599

37. Fratiglioni L, Paillard-Borg S, Winblad B. An active and socially integrated lifestyle in late life might protect against dementia. Lancet Neurol 2004;3(06):343-353

38. Rigters SC, Bos D, Metselaar M, et al. Hearing impairment is associated with smaller brain volume in aging. Front Aging Neurosci 2017 (epub ahead of print). Doi: 10.3389/fnagi.2017.00002
39. Lin FR, Ferrucci L, An Y, et al. Association of hearing impairment with brain volume changes in older adults. Neuroimage 2014;90:84-92

40. Wayne RV, Johnsrude IS. A review of causal mechanisms underlying the link between age-related hearing loss and cognitive decline. Ageing Res Rev 2015;23(Pt B):154-166

41. Gates GA, Gibbons LE, McCurry SM, Crane PK, Feeney MP, Larson EB. Executive dysfunction and presbycusis in older persons with and without memory loss and dementia. Cogn Behav Neurol 2010;23(04):218-223

42. Wong LLN, Yu JKY, Chan SS, Tong MC. Screening of cognitive function and hearing impairment in older adults: a preliminary study. BioMed Res Int 2014;2014:867852

43. Dupuis K, Pichora-Fuller MK, Chasteen AL, Marchuk V, Singh G, Smith SL. Effects of hearing and vision impairments on the Montreal Cognitive Assessment. Neuropsychol Dev Cogn B Aging Neuropsychol Cogn 2015;22(04): 413-437

44. Varela-Nieto I, Murillo-Cuesta S, Rodríguez-de la Rosa L, Lassatetta L, Contreras J. IGF-I deficiency and hearing loss: molecular clues and clinical implications. Pediatr Endocrinol Rev 2013;10 (04):460-472

45. Rodríguez-de la Rosa L, Lassaletta L, Calvino M, Murillo-Cuesta S, Varela-Nieto I. The role of insulin-like growth factor 1 in the progression of age-related hearing loss. Front Aging Neurosci 2017;9:411

46. Deal JA, Albert MS, Arnold M, et al. A randomized feasibility pilot trial of hearing treatment for reducing cognitive decline: results from the Aging and Cognitive Health Evaluation in Elders Pilot Study. Alzheimers Dement (N Y) 2017;3(03): 410-415

47. Miller G, Miller C, Marrone N, Howe C, Fain M, Jacob A. The impact of cochlear implantation on cognition in older adults: a systematic review of clinical evidence. BMC Geriatr 2015;15:16

48. Vega A. Present neuropsychological status of subjects implanted with auditory prostheses. Ann Otol Rhinol Laryngol Suppl 1977;86(3 Pt 3, Suppl 38):57-60

49. Crary WG, Wexler M, Berliner KI, Miller LW. Psychometric studies and clinical interviews with cochlear implant patients. Ann Otol Rhinol Laryngol Suppl 1982;91(2, Pt 3):55-58

50. Aplin DY. Psychological assessment of multichannel cochlear implant patients. J Laryngol Otol 1993;107(04):298-304

51. Mosnier I, Bebear J-P, Marx M, et al. Improvement of cognitive function after cochlear implantation in elderly patients. JAMA Otolaryngol Head Neck Surg 2015;141(05):442-450 
52. Cosetti MK, Pinkston JB, Flores JM, et al. Neurocognitive testing and cochlear implantation: insights into performance in older adults. Clin Interv Aging 2016;11:603-613

53. Jayakody DMP, Friedland PL, Nel E, Martins RN, Atlas MD, Sohrabi HR. Impact of cochlear implantation on cognitive functions of older adults: pilot test results. Otol Neurotol 2017;38(08): e289-e295

54. Völter C, Götze L, Dazert S, Falkenstein M, Thomas JP. Can cochlear implantation improve neurocognition in the aging population? Clin Interv Aging 2018;13:701-712

55. Mosnier I, Vanier A, Bonnard D, et al. Long-term cognitive prognosis of profoundly deaf older adults after hearing rehabilitation using cochlear implants. J Am Geriatr Soc 2018;66(08): 1553-1561

56. Sarant J, Harris D, Busby P, et al. The effect of cochlear implants on cognitive function in older adults: initial baseline and 18-month follow up results for a prospective international longitudinal study. Front Neurosci 2019;13:789

57. Gurgel RK, Duff K, Foster NL, Urano KA, deTorres A. Evaluating the impact of cochlear implantation on cognitive function in older adults. Laryngoscope 2021. Doi: 10.1002/lary.29933 (in press)

58. Luxford WMAd Hoc Subcommittee of the Committee on Hearing and Equilibrium of the American Academy of Otolaryngology-Head and Neck Surgery. Minimum speech test battery for postlingually deafened adult cochlear implant patients. Otolaryngol Head Neck Surg 2001;124(02): 125-126

59. Feeny D, Furlong W, Torrance GW, et al. Multiattribute and single-attribute utility functions for the health utilities index mark 3 system. Med Care 2002; 40(02):113-128

60. Hawthorne G, Richardson J, Osborne R. The Assessment of Quality of Life (AQoL) instrument: a psychometric measure of health-related quality of life. Qual Life Res 1999;8(03):209-224

61. Hinderink JB, Krabbe PFM, Van Den Broek P. Development and application of a health-related quality-of-life instrument for adults with cochlear implants: the Nijmegen cochlear implant questionnaire. Otolaryngol Head Neck Surg 2000;123(06): 756-765

62. McRackan TR, Hand BN, Velozo CA, Dubno JRCochlear Implant Quality of Life Development Consortium. Cochlear implant quality of life (CIQOL): development of a profile instrument (CIQOL-35 Profile) and a global measure (CIQOL-10 Global). J Speech Lang Hear Res 2019;62(09):3554-3563

63. McRackan TR, Hand BN, Velozo CA, Dubno JRCochlear Implant Quality of Life Development Consortium. Development of the cochlear implant quality of life item bank. Ear Hear 2019;40(04): 1016-1024

64. Robinson K, Gatehouse S, Browning GG. Measuring patient benefit from otorhinolaryngological surgery and therapy. Ann Otol Rhinol Laryngol 1996;105(06):415-422

65. Ventry IM, Weinstein BE. The hearing handicap inventory for the elderly: a new tool. Ear Hear 1982;3(03):128-134

66. Newman CW, Weinstein BE, Jacobson GP, Hug GA. The hearing handicap inventory for adults: psychometric adequacy and audiometric correlates. Ear Hear 1990;11(06):430-433

67. Gatehouse S, Noble W. The speech, spatial and qualities of hearing scale (SSQ). Int J Audiol 2004; 43(02):85-99

68. Hirschfelder A, Gräbel S, Olze H. The impact of cochlear implantation on quality of life: the role of audiologic performance and variables. Otolaryngol Head Neck Surg 2008;138(03):357-362

69. Lassaletta L, Castro A, Bastarrica M, de Sarriá MJ, Gavilán J. Quality of life in postlingually deaf patients following cochlear implantation. Eur Arch Otorhinolaryngol 2006;263(03):267-270

70. Chung J, Chueng K, Shipp D, et al. Unilateral multi-channel cochlear implantation results in significant improvement in quality of life. Otol Neurotol 2012;33(04):566-571

71. Litovsky R, Parkinson A, Arcaroli J, Sammeth C. Simultaneous bilateral cochlear implantation in adults: a multicenter clinical study. Ear Hear 2006;27(06):714-731

72. Kamal SM, Robinson AD, Diaz RC. Cochlear implantation in single-sided deafness for enhancement of sound localization and speech perception. Curr Opin Otolaryngol Head Neck Surg 2012;20 (05):393-397

73. Klop WM, Boermans PP, Ferrier MB, van den Hout WB, Stiggelbout AM, Frijns JH. Clinical relevance of quality of life outcome in cochlear implantation in postlingually deafened adults. Otol Neurotol 2008;29(05):615-621

74. McRackan TR, Hand BN, Velozo CA, Dubno JR. Association of demographic and hearing-related factors with cochlear implant-related quality of life. JAMA Otolaryngol Head Neck Surg 2019;145 (05):422-430

75. McRackan TR, Bauschard M, Hatch JL, et al. Meta-analysis of quality-of-life improvement after cochlear implantation and associations with speech recognition abilities. Laryngoscope 2018;128(04): 982-990

76. Francis HW, Chee N, Yeagle J, Cheng A, Niparko JK. Impact of cochlear implants on the functional health status of older adults. Laryngoscope 2002; 112(8, Pt 1):1482-1488

77. Capretta NR, Moberly AC. Does quality of life depend on speech recognition performance for 
adult cochlear implant users? Laryngoscope 2016; 126(03):699-706

78. Kou BS, Shipp DB, Nedzelski JM. Subjective benefits reported by adult Nucleus 22-channel cochlear implant users. J Otolaryngol 1994;23 (01):8-14

79. Cruickshanks KJ, Wiley TL, Tweed TS, et al; The Epidemiology of Hearing Loss Study. Prevalence of hearing loss in older adults in Beaver Dam, Wisconsin. Am J Epidemiol 1998;148(09): 879-886

80. Blanchfield BB, Feldman JJ, Dunbar JL, Gardner EN. The severely to profoundly hearing-impaired population in the United States: prevalence estimates and demographics. J Am Acad Audiol 2001;12 (04):183-189

81. Sorkin DL. Cochlear implantation in the world's largest medical device market: utilization and awareness of cochlear implants in the United States. Cochlear Implants Int 2013;14(Suppl 1): S4-S12

82. Clegg A, Young J, Iliffe S, Rikkert MO, Rockwood K. Frailty in elderly people. Lancet 2013;381 (9868):752-762

83. Fried LP, Tangen CM, Walston J, et al; Cardiovascular Health Study Collaborative Research Group. Frailty in older adults: evidence for a phenotype. J Gerontol A Biol Sci Med Sci 2001; 56(03):M146-M156
84. Subramaniam S, Aalberg JJ, Soriano RP, Divino CM. New 5-factor modified frailty index using American College of Surgeons NSQIP Data. J Am Coll Surg 2018;226(02):173-181.e8

85. Velanovich V, Antoine H, Swartz A, Peters D, Rubinfeld I. Accumulating deficits model of frailty and postoperative mortality and morbidity: its application to a national database. J Surg Res 2013;183(01):104-110

86. Adams P, Ghanem T, Stachler R, Hall F, Velanovich V, Rubinfeld I. Frailty as a predictor of morbidity and mortality in inpatient head and neck surgery. JAMA Otolaryngol Head Neck Surg 2013;139(08):783-789

87. Casazza GC, McIntyre MK, Gurgel RK, et al. Increasing frailty, not increasing age, results in increased length of stay following vestibular schwannoma surgery. Otol Neurotol 2020;41(10): e1243-e1249

88. Dicpinigaitis AJ, Kalakoti P, Schmidt M, et al. Associations of baseline frailty status and age with outcomes in patients undergoing vestibular schwannoma resection. JAMA Otolaryngol Head Neck Surg 2021;147(07):608-614

89. Aylward A, Murphy-Meyers M, Allen CM, Patel NS, Gurgel RK. Frailty and quality of life after cochlear implantation in older adults. Otolaryngol Head Neck Surg 2021 (epub ahead of print). Doi: 10.1177/01945998211004589 